\title{
(2) OPEN ACCESS \\ Modelling the determinants of health and cancers as perceived by children: using imagery as a mediator of expression and narration
}

\author{
Chloé Gay $\odot,{ }^{1}$ Maeliane Deyra, ${ }^{1}$ Pauline Berland, ${ }^{2}$ Laurent Gerbaud, ${ }^{2}$ Frank Pizon ${ }^{1}$
}

'Université Clermont Auvergne, CNRS, SIGMA Clermont, Institut Pascal, F-63000, ClermontFerrand, France

2Université Clermont Auvergne, CHU, CNRS, SIGMA Clermont, Institut Pascal, F-63000, Clermont-Ferrand, France

Correspondence to Dr Chloé Gay, Public Health, Institut Pascal, Aubière 63178, France; chloe.gay@uca.fr

Received 3 September 2020 Revised 30 December 2020 Accepted 3 January 2021
D) Check for updates

(C) Author(s) (or their employer(s)) 2021. Re-use permitted under CC BY-NC. No commercial re-use. See rights and permissions. Published by BMJ.

To cite: Gay C, Deyra M, Berland $\mathrm{P}$, et al.

Arch Dis Child Epub ahead of print: [please include Day Month Year]. doi:10.1136/ archdischild-2020-320601

\section{ABSTRACT}

Objectives To model and analyse conceptions of determinants of health and cancer that are expressed and perceived by school children aged $6-11$ based on a multiphase qualitative protocol.

Methodology This is a multicentric, qualitative study of human and social sciences conducted among school children aged $6-11$ years old. Two different tools were used, e.Photoexpression and Photonarration, in four French schools. This innovative and exploratory method addresses global health during the first phase (e.Photoexpression) and the theme of cancer during the second phase (Photonarration). The children express themselves through photography and narration.

Results 1498 qualitative productions were made by 381 children aged $6-11$ years old. The analysis of these productions of expression and narration through images allowed modelling of determinants of health and cancer as perceived by children through 7 fields and 28 categories. The conceptions of determinants of health and child cancer refer to rationalities that are centred on individual determinants (76\%), minimise environmental determinants $(20 \%)$ and conceal the parameters of access to healthcare and social services (3\%).

Discussion These findings provide new data to the international literature on children's perceptions of determinants of health and cancer. These research findings, which can be applied to interventions and current practices, will enable prevention workers to act more effectively, closer to children's perceptions and needs.

\section{INTRODUCTION}

Concepts of health are defined as structuring the individual in their individual and collective aspects and in the way they characterise the determinants of 'their' health by adopting behaviours that may or may not be consistent with what they think is going on. ${ }^{1}$

Currently, the determinants of health are defined by the WHO as 'the personal, social, economic and environmental factors that determine the state of health of individuals and populations'. ${ }^{2}$ They can be individual or collective, innate or acquired, and interact with one another.

Models presenting determinants of health are widely available in the literature. ${ }^{3}{ }^{4}$ Dahlgren and Whitehead's ${ }^{5}$ model is still the foundation and presents the determinants of health under four levels. This model was adapted for children by Bronfenbrenner, ${ }^{6}$ as well as by Dahlgren and Whitehead, ${ }^{3}$ in

\section{What is already known on this topic?}

The influence of determinants of health on the health of individuals is well documented.

- The current issue is therefore to better understand how they work and how we can intervene most effectively in prevention.

- Models presenting determinants of health are available in the literature, including Dahlgren and Whitehead's model, adapted to children by Bronfenbrenner and by Dahlgren and Whitehead.

\section{What this study adds?}

- This original research is the first to model the determinants of health and cancer as expressed and perceived by 381 children aged 6-11.

- Our innovative multiphase methodology using photography and images has enabled us to collect 1498 qualitative productions from children.

- Conceptions of determinants of children refer to rationalities on individual determinants, minimise environmental determinants and conceal parameters of access to healthcare and social services.

2019. ${ }^{7}$ However, a review of the literature ${ }^{8}$ shows that few international publications involved a qualitative or mixed methodology focusing on children's conceptions of health and cancer. ${ }^{9}{ }^{10}$ No model to represent the determinants of health as perceived by children is available in the literature. For decades, prevention and health education policies have been built on the basis of very little qualitative research data. ${ }^{11}$ Taking children's voices into account by focusing on their conceptions of determinants of health and cancer from an early age, using a robust, standardised and reproducible qualitative methodology, seems indispensable in understanding current and future behaviours. ${ }^{12}$ Health is built from childhood, and the measurement of social determinants provides evidence that is the basis for political action to address these determinants and to achieve changes in these behaviours.

The influence of determinants of health on the health of individuals is widely proven. ${ }^{13}$ The increase in cancer and the general health status of the population are both linked to several similar 
factors, including population growth, ageing and changes in the prevalence of certain causes of pathologies associated with social and economic conditions. This is particularly true in fastgrowing economies, where there is a trend in cancers related to poverty and infections, with today's cancers associated with the lifestyle of industrialised countries. ${ }^{14}$ Nevertheless, for majority of cancers, the causes are linked to environmental determinants, where there is little scope for action at the individual level. ${ }^{15}$ The current question is therefore to better understand how they work and how we can intervene in prevention as effectively as possible. $^{16}$

The objective of this study is to model the conceptions of health determinants and cancers as expressed and perceived by school children aged 6-11.

\section{METHODOLOGY}

\section{Framework of the study}

This is a qualitative study of human and social sciences carried out among school children. This study was conducted in four schools in the Auvergne-Rhône-Alpes region in France. The recruitment period took place from January to March 2019. In this collection, 381 children between the ages of 6 and 11 participated. Three children had a painful experience with cancer (loss of a parent). These families were interviewed with the teacher beforehand in order to answer questions and to avoid any possible anxiety related to the study. All children were offered the opportunity to leave the session and comment on a situation that affected them. None of the children chose this option.

\section{Data collection}

Phase 1: 'e.Photoexpression'

This is an image mediation tool consisting of a corpus of 40 colour photographs and is copyrighted. ${ }^{1}$ The approach in which this corpus of 40 photographs was founded is very open and intended to promote the emergence of health conceptions. It has been used in other studies, notably in the field of addiction. ${ }^{17} 18$

In this study, this tool is used to help identify the determinants perceived as having a positive or negative influence on one's health. The children chose 2 of the 40 images that best responded to the following instructions: 'Choose an image that you think represents good health' and 'Choose an image that you think represents poor health'. Each child presented in writing the reasons for their choice of images.

Photography makes it possible to co-construct a reality (or the object of research) in this triadic interaction between the researcher, the photographer and the subject. ${ }^{19}$ The photograph 'made available' by the researcher is thus the object of a reappropriation by the subject who proposes a personal interpretation.

\section{Phase 2: 'Photonarration'}

Photonarration consists of making conception systems emerge from a cut-out, assembling collage of images from magazines. ${ }^{1}$ Through its large panel of images, it allows a free choice of expression and use of conceptions. The following are the eligibility criteria for the magazines proposed to children: a thematic diversity (sports, nature, hobbies, health and so on) and targeting different ages (children, adults and seniors). The corpus is enriched by leaflets from large supermarkets (food, leisure, other consumer products and so on) or pharmaceutical products (medicines, hygiene products and so on). Each production (A3) is associated with a text describing the nature of this production: 'In the images you have chosen, what for you represents the cause of cancer?' and 'In the images you have chosen, what represents that which prevents cancer?'

\section{Variables}

The data analysed are the collected verbatims. The classification of the verbatims collected from the students is represented by strata under two different levels: fields and categories. The fields represent a dominant idea that groups and structures the categories. The category groups the elements of a vocabulary or information, organised according to a certain number of common semantic or grammatical criteria. This classification works in an ascending and descending manner. Based on students' productions and the collected verbatims, each point raised by the interviewed students was reported and classified in an Excel spreadsheet. The converging points were grouped by blocks of meaning. ${ }^{20}$ According to the level of detail of the blocks of meaning, we identify the level at which the student is situated: the larger the block of meaning, the closer we get to the field; the smaller the block of meaning, the closer we get to the category.

In order to preserve authenticity, finesse and detail of the elements covered by the students, fields and categories have been created according to the degree of granulometry of students' remarks. This classification produces a funnel effect, with a densification of ideas as one goes from level to level. This is because there is more detail and description in the 'category' row than in the 'field' row. These details allow for additional detail, always with a view to staying as close as possible to the children's words.

The analysis that was conducted was not linear, but rather circular. We constantly travelled back and forth, allowing us to carry out back-testing at all levels: between the source data (images, verbatims and oral explanations of the children), the conceptual and theoretical model of the determinants of health, and the exchanges with the multidisciplinary research team.

This study requires simultaneous data collection and qualitative analysis. Indeed, it is the analysis that allowed us to complete the recruitment of the schools when the data saturation point was reached.

All data were collected by the same interviewers. Double coding was used for data analysis. In the event of a dispute, a third party was consulted.

Statistical analyses were carried out using SAS V.9.40 software.

\section{Ethical considerations}

This study was conducted in accordance with the recommendations of the 'consolidated criteria for reporting qualitative research (COREQ)'. Recruitment was done on a voluntary basis by the teachers of the Auvergne-Rhône-Alpes Academy. All children and parents who gave their consent participated in this study. $^{21}$

The methodology allows us to approach the theme of cancer from the point of view of children in a benevolent manner, within an ethical regulatory framework. In order to reassure adults (families and teachers) who may consider this complex topic unsuitable for children, an andragogical work of information and presentation of the research was carried out in the field. A verbal explanation on the use of research data was provided to the children. ${ }^{21}$ Their consent was required for conservation of their productions. These interventions were meaningful for the children and they showed real enthusiasm to participate in the research. A document explaining the context of the research was provided. 


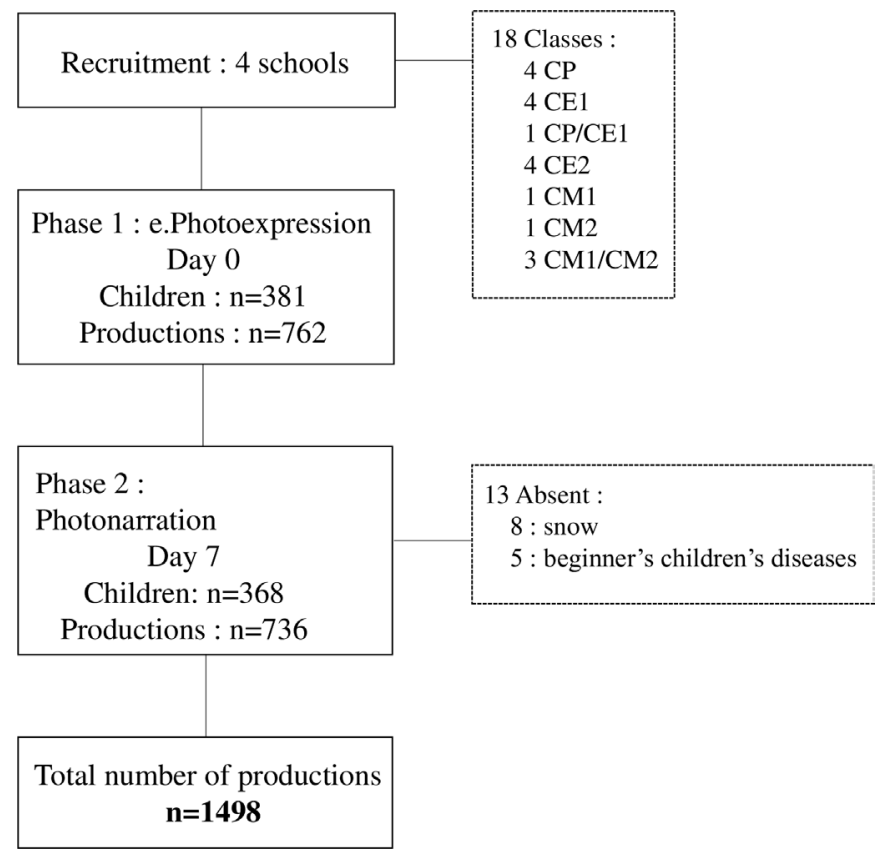

Figure 1 Flow diagram. Data were collected from four French elementary schools in the Auvergne-Rhône-Alpes region. During phase 1 of the collection, 381 children from 6 to 11 years participated and produced 762 productions. In phase 2, 368 children were interviewed and 736 productions were collected. 186 girls (49\%) and 195 boys (51\%) participated in the collection. The breakdown by class was as follows: $25 \%$ preparatory class (CP 6-7 years old), $21 \%$ first-year elementary class (CE1 7-8 years old), 24\% second-year elementary class (CE2 8-9 years old), 15\% first-year middle class (CM1 9-10 years old) and $14 \%$ second-year middle class (CM2 10-11 years old). A total of 1498 productions were made (4 productions per student). The reasons of absence for 13 students between sessions 1 and 2 were snow for 8 children and benign childhood illnesses for 5 others ( 2 gastroenteritis, 1 rhinopharyngitis and 2 angina).

\section{RESULTS}

Figure 1 illustrates the descriptive data for this study.

Figure 2 presents the conceptions of determinants of health as expressed by children aged 6-11, showing 7 fields and 28 categories that fit into the biopsychosocial model.

Qualitative analysis of conversations with children revealed 7 fields and 28 categories concerning the twothemes addressed during the interventions: health (e.Photoexpression) and cancer (Photonarration) (figure 2).

The phase 1 results (e.Photoexpression), showing the breakdown of conceptions of determinants of health across 7 fields and 28 categories as expressed by 381 children aged $6-11$ years, along with their distribution into conceptions favourably or unfavourably influencing health, are illustrated in figure 3.

\section{Phase 1 descriptive results (e.Photoexpression, figure 3)}

- The 'link with a health theme' field was addressed by $56 \%$ of children; 91\% had a favourable conception of health ('physical activity (PA) and sports', 'diet' and 'airing out' categories) and $24 \%$ had an unfavourable conception of health ('physical activity and sports', 'unhealthy diet' and 'screen/ audiovisual pollution' categories).

- The 'health capital' field was addressed by 49\% of children; $8 \%$ had a favourable conception of health ('children' and 'being able to do: PA/other activities' categories) and 95\%

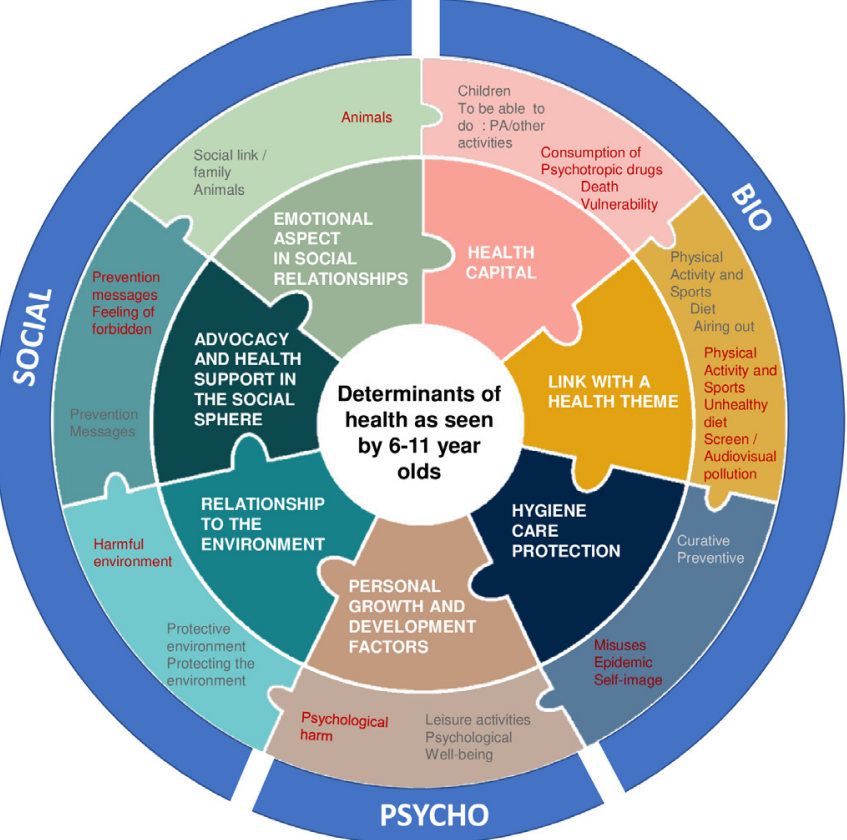

Figure 2 Modelling the determinants of health as expressed and perceived by 381 children aged $6-11$. The model of children's conceptions of determinants of health and cancer is represented as a puzzle because all fields and categories influence each other and are linked, interconnected and inseparable. The first circle represents the seven fields. The second circle represents the 28 categories corresponding to their area of colour. The fields represent individual and/or collective determinants and may induce 'favourable' or 'unfavourable' conceptions of health as perceived by children. The fields correspond to a dominant and leading idea, and to fields of general and global elements that group and structure the categories. It is the grouping of verbatims by blocks of meaning that made it possible to determine these fields. Each field encompasses one overarching idea related to a determinant of health. A category corresponds to a set of common components that have common characteristics. It groups together the elements of a vocabulary or information, organised according to a certain number of common semantic or grammatical criteria. Catégories adds a descriptive element to the field it belongs to. Each category is correlated to the field it belongs to. It allows us to respect children's words by providing additional information to their source field, such as the favourable (green) or unfavourable (red) conceptions that children have of health.

had an unfavourable conception of it ('consumption of psychotropic drugs', 'death' and 'vulnerability/you can catch it if you are already sick' categories).

- The 'relationship to the environment' field was addressed by $47 \%$ of children; $37 \%$ had a favourable conception of health ('protective environment' and 'protecting the environment' categories) and $76 \%$ had an unfavourable conception of it ('harmful environment' category).

- The 'personal growth and development factors' field was addressed by $24 \%$ of children; $87 \%$ had a favourable view of health ('leisure activities' and 'psychological well-being' categories) and 25\% had an unfavourable view ('psychological harms' category).

- The 'emotional aspect in social relationships' field was addressed by $16 \%$ of children; $84 \%$ had a favourable conception of health ('social bond/family' and 'animals' 


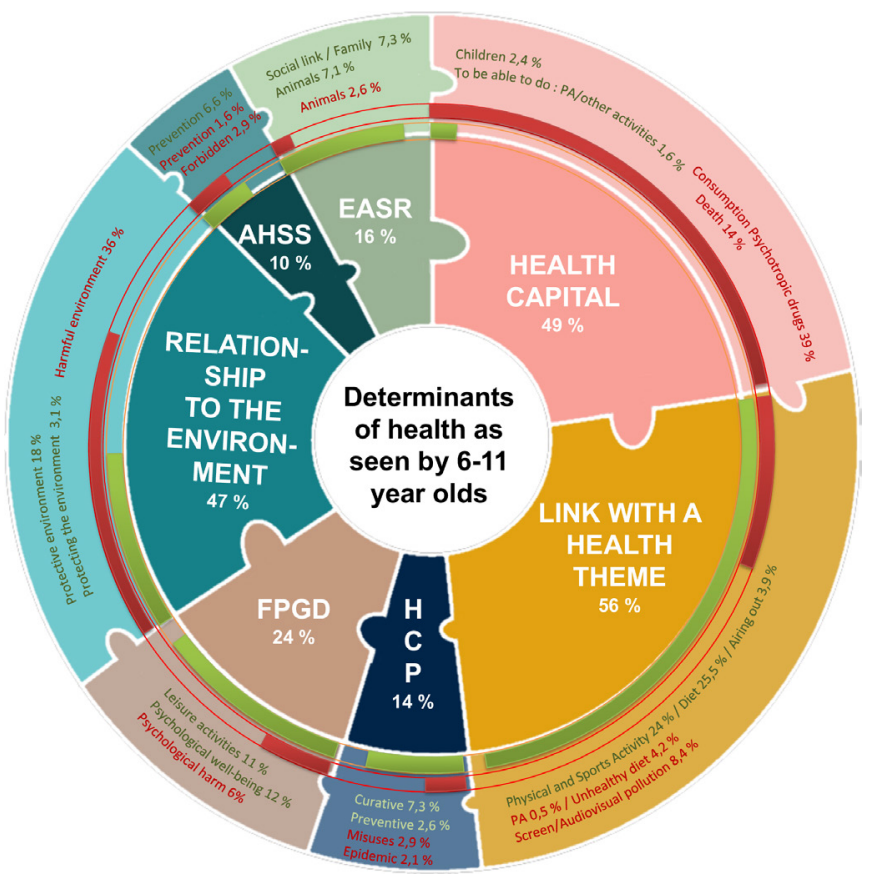

Figure 3 Modelling the determinants of health as expressed by 381 children: the relative weight of the fields and categories for e.Photoexpression. The analysis revealed a real imbalance in the distribution of favourable and unfavourable conceptions within the fields, whether they were dominant or not. For only two fields, 'depletion of health capital' and 'relationship to the environment', the weight of unfavourable conceptions was predominant. These unfavourable conceptions were represented by the categories 'consumption of psychotropic drugs' and 'harmful environment'. Children mentioned an average of 2 (0.8) fields and 2.6 (0.9) categories. The first circle represents the percentage of fields covered by the children in relation to the total number of children. The second circle represents the percentage of categories corresponding to their field of colour, relative to the total number of children. The categories in green represent the categories that evoke health-promoting conceptions, and the categories in red represent the categories that evoke unhealthy conceptions. The favourable and unfavourable shares of each field are represented by the green and red circle arcs (percentage calculated in relation to the number of children who have addressed the field). Children are given the opportunity to mention more than one field and category. AHSS, advocacy and health support in the social sphere; EASR, emotional aspect in social relationships; FPGD, factors for personal growth and development; HCP, hygiene, care and protection; PA, physical activity.

categories) and $16 \%$ had an unfavourable conception of health ('animals' category).

- The 'hygiene/care/protection' field was addressed by $14 \%$ of children; $72 \%$ had a favourable conception of health ('curative' and 'preventive' categories) and 36\% had an unfavourable conception of health ('misuse', 'epidemic' and 'self-image' categories).

- The 'advocacy and health support in the social sphere' field was addressed by $10 \%$ of children; $64 \%$ had a favourable conception of health ('prevention messages' category) and $44 \%$ had an unfavourable conception of health ('prevention message' and 'feeling of being forbidden' categories).

The phase 2 results (Photonarration), showing the breakdown of conceptions of determinants of cancer across 7 fields and 28 categories as expressed by 368 children aged $6-11$ years, along

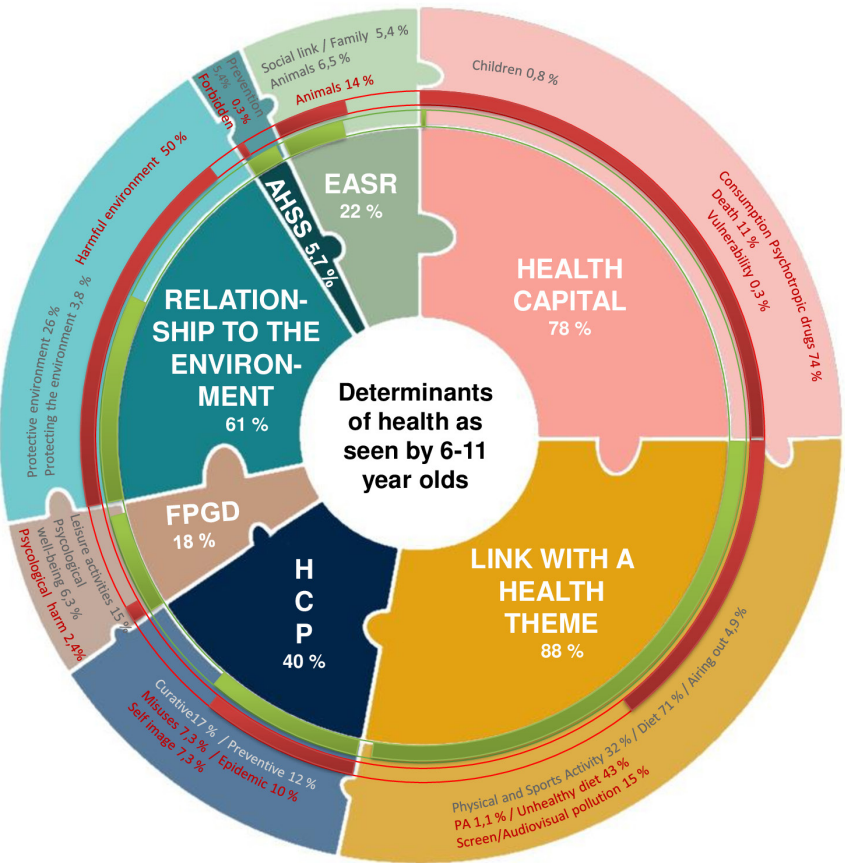

Figure 4 Modelling the determinants of cancer as expressed by 368 children: the relative weight of the fields and categories for Photonarration. The analysis revealed an imbalance in the distribution of favourable and unfavourable conceptions within the fields, whether they were dominant or not. For three fields, 'depletion of health capital', 'relationship to the environment' and 'the affective aspect in social relationships', the weight of unfavourable conceptions is predominant (categories: 'consumption of psychotropic drugs (alcohol and tobacco)', 'harmful environment (automobile pollution)' and 'animals'). This methodology allows children to link disciplines together given that, on average, 2.6 (1.3) fields and 4.8 (2.3) categories were mentioned. These results show that by adapting to children's writing level (dictated to the adult), this methodology gives a heterogeneous panel of children (age and social context) the opportunity to express themselves freely and to assemble and communicate conceptions that may or may not reveal themselves in a more or less distinct manner, with the subject himself/herself not necessarily having access to his/her own conceptions of health. The first circle represents the percentage of areas covered by the children in relation to the total number of children. The second circle represents the percentage of categories corresponding to their field of colour, relative to the total number of children. The categories evoking favourable, cancer-protective conceptions are in green, and the categories evoking unfavourable, cancer-causing conceptions are in red. The favourable and unfavourable shares of each field are represented by the green and red circle arcs (percentage calculated in relation to the number of children who have approached the field). Children are given the opportunity to mention several fields and categories. AHSS, advocacy and health support in the social sphere; EASR, emotional aspect in social relationships; FPGD, factors for personal growth and development; HCP, hygiene, care and protection; PA, physical activity.

with their distribution into conceptions favourably or unfavourably influencing health, are illustrated in figure 4.

\section{Phase2 : Descriptive results (Photonarration, figure 4)}

- The 'link with a health theme' field was addressed by $88 \%$ of children; 92\% had a protective conception of cancer ('physical activity and sports', 'diet' and 'airing out' categories) and 58\% had an unfavourable conception which 'leads' to 
cancer ('physical activity and sports', 'unhealthy diet' and 'screen/audiovisual pollution' categories).

- The 'health capital' field was addressed by $78 \%$ of children; $1 \%$ had a protective conception of cancer ('children' and 'being able to do: PA/other activities' categories) and 100\% had an unfavourable conception of it ('consumption of psychotropic drugs', 'death' and 'vulnerability/you can get it if you are already sick' categories).

- The 'relationship to the environment' field was addressed by $61 \%$ of children; $45 \%$ had a protective conception of cancer ('protective environment' and 'protecting the environment' categories) and $83 \%$ had an unfavourable conception of cancer ('harmful environment' category).

- The 'hygiene/care/protection' field was addressed by $40 \%$ of children; $62 \%$ had a protective conception of cancer ('curative' and 'preventive' categories) and 55\% had an unfavourable conception of cancer ('misuse', 'epidemic' and 'self-image' categories).

- The 'emotional aspect in social relationships' field was addressed by $22 \%$ of children; $45 \%$ had a protective conception of cancer ('social bond/family' and 'animals' categories) and $63 \%$ had an unfavourable conception of cancer ('animals' category).

- The 'personal growth and development factors' field was addressed by $18 \%$ of children; $95 \%$ had a protective conception of cancer ('leisure activities' and 'psychological wellbeing' categories) and 14\% had an unfavourable conception of cancer ('psychological harm' category).

- The 'advocacy and health support in the social sphere' field was addressed by $6 \%$ of children; $95 \%$ had a protective conception of cancer ('prevention messages' category) and $5 \%$ had an unfavourable conception of cancer ('prevention message' and 'feeling of being forbidden' categories).

\section{DISCUSSION}

e.Photoexpression and Photonarration allowed the collection of 1498 qualitative productions carried out by 381 children from 6 to 11 years old. The analysis of these productions of expression and narration through images offers a model of the determinants of health and cancer as perceived by children through 7 fields and 28 categories.

The conceptions of determinants of health and child cancer refer to rationalities centred on individual determinants (76\%), minimise environmental determinants (20\%) and obscure the parameters of access to healthcare and social services (3\%).

The individual determinants echo the 'personal lifestyle factors' and 'social and community networks' model of Dahlgren and Whitehead in 1991, ${ }^{12}$ as well as the 'health behavior of parents and children' model adapted from Bronfenbrenner and from Dahlgren and Whitehead in 2019. ${ }^{7}$ These individual determinants are represented in our results by the fields 'link with a health theme', 'health capital' and 'hygiene, care, protection'. They reflect the discourse expressed by those around them and the prevention messages disseminated by the media, and exhaustively represent the modifiable risk factors for cancer. ${ }^{22}$ Children are essentially self-focused on personal behaviours and aspects of their daily life and events that affect them closely, with immediate leverage for action. They are also represented by personal and social skills, ${ }^{23}$ through the 'personal growth and development factors' and 'emotional aspect in social relationships' fields. The children's discourse focuses on their personal feelings, pleasures and displeasures such as leisure activities, well-being, uneasiness, social ties and love. These results are representative of children's psychoemotional development and the socialisation phenomenon. As they grow up, their interactions with the social world will gradually help them to decentralise and discover their entire living environment. ${ }^{24}$

According to the children, individual determinants have a predominantly positive influence on health. Only the " health capital' field gives a negative and anxiety-provoking entry to the determinants of health. This can be explained by the presence of very negative categories linked to this field, such as death and the consumption of psychotropic drugs (alcohol and tobacco).

In its fourth level, Dahlgren and Whitehead's theoretical model $^{5}$ 'socio-economic, cultural and environmental conditions' encompasses the factors that influence society as a whole. The environmental determinants presented in our results are grouped under the 'environmental factors' and 'advocacy and support in the social sphere' fields and are under-represented (24\%).

The categories in the 'environmental factors' field include factors that are unfavourable to health (pollution, feeling of insecurity, precariousness and negative economic situation) and factors favourably influencing health (environmental protection and positive economic situation). Unfavourable factors take precedence over environmental factors that have a beneficial influence on health, making this an anxiety-provoking field from the point of view of children. Children are concerned about environmental pollution linked to human activities (cars) and the importance of having a remunerative and fulfilling job in the future, but do not address the issue of risks linked to occupational exposure. They remain mostly centred on microrepresentations that affect an environment very close to their daily life and obscure the global context of society, such as the economic situation of a country, its political context and the conditions of the labour market.

The parameters of accessibility of health services, social assistance, outreach services, education, housing and childcare workplaces are obscured by children. ${ }^{5}$ The verbatims that mention these are grouped under the 'advocacy and support in the social sphere' field through the 'prevention messages' and 'feeling of being forbidden' categories. Highlighting the underrepresentation of the themes of accessibility of education, social and health services, as well as the global, political, economic and cultural context, and the over-representation of individual determinants, points to a personal responsibility, or even guilt, on the part of the population in its ability and willingness to be in good or poor health. Indeed, children stress the importance of a healthy and balanced diet as well as regular physical activity, but do not mention access to food and physical activity.

Conducting this study internationally would allow us to confront the conceptions of children from different countries. Furthermore, extending this study to secondary education (middle and high schools) would help to observe whether children acquire the aspect of global context and systems related to health and cancer determinants as they get older.

Our methodology of investigation in two successive phases (e.Photoexpression and Photonarration) allowed us to reveal that children from the earliest age have the same conceptions of determinants of health as presented in the literature. ${ }^{57232526}$ The approach using the theme of global health and the restricted image choice (good health and poor health) guarantees a stepby-step progression, while respecting the cognitive process of adaptation and acceptance of children's thought process. ${ }^{27} \mathrm{We}$ observed a diversity of perspectives from the earliest age. These results attest to the coherence, quality and density of children's statements revealed by this methodology. Children have their own conceptions and are able to structure their thinking in an 
explanatory logic, so it is essential to consider and take them into account when addressing them.

These results show that by adapting to students' writing level (taken down by adults in preparatory courses), this methodology gives a heterogeneous panel of students (age and social context) the opportunity to express themselves freely and to assemble and communicate conceptions that may or may not reveal themselves in a more or less distinct manner, with the subject himself/ herself not necessarily having access to his/her own conceptions of health. ${ }^{1}$

Knowledge and consideration of the determinants of health, as seen by children in prevention and health education strategies, are essential to meet the current and future needs of this population as closely as possible. In addition to enriching the literature in this little-documented field, they would enable professionals to carry out highly targeted preventive actions that are more effective and better adapted to children.

Acknowledgements The authors would like to thank the children and teachers who participated in this research, as well as the Institut Pascal laboratory, particularly the DeciSiPH research team we were a part of, and the Public Health Service of the $\mathrm{CHU}$ in Clermont-Ferrand for welcoming the research team. We also thank the Conseil Départemental de I'Allier for granting doctoral scholarship.

Contributors CG produced the original draft, and MD, FP and LG provided critical revisions. PB realised the statistical analyses. All authors have seen and approved the final version.

Funding This original research is funded by 'Ligue Nationale Contre le Cancer'.

Competing interests None declared.

Patient consent for publication Not required.

Ethics approval This research obtained an ethical certificate from the Comité de Protection de Personne sud EST VI (France) (South East Committee of Protection of Persons VI).

Provenance and peer review Not commissioned; externally peer reviewed.

Data availability statement Data are available upon reasonable request to the corresponding author.

Open access This is an open access article distributed in accordance with the Creative Commons Attribution Non Commercial (CC BY-NC 4.0) license, which permits others to distribute, remix, adapt, build upon this work non-commercially, and license their derivative works on different terms, provided the original work is properly cited, appropriate credit is given, any changes made indicated, and the use is non-commercial. See: http://creativecommons.org/licenses/by-nc/4.0/.

ORCID iD

Chloé Gay http://orcid.org/0000-0002-8614-0076

\section{REFERENCES}

1 Pizon F. Health education and prevention. London: ISTE - Wiley, 2019

2 Organisation mondiale de la santé,. Glossaire de la promotion de la santé, 1999.

3 Dahlgren G, Whitehead M. Tackling inequalities in health: what can we learn from what has been tried? Working paper prepared for the King's Fund International
Seminar on Tackling Inequalities in Health. Ditchley Park, Oxfordshire: London, King's Fund, 1993. Accessible in: Dahlgren G, and Whitehead M European strategies for tackling social inequities in health Levelling up Part 2 Copenhagen: World Health Organisation Regional Office for Europe 2007.

4 InKaplan GAMarmot M, Wilkinson R, eds. Social determinants of health. 2nd edn. Oxford: Oxford University Press, 2006. ISBN: 9780198565895

5 Whitehead M, Dahlgren G. What can be done about inequalities in health? The Lancet. 26 oct 1991:338:1059-63.

6 Bronfenbrenner U. The ecology of human development: experiments by nature and design. Cambridge: Harvard University Press, 1979.

7 Pearce A, Dundas R, Whitehead M, et al. Pathways to inequalities in child health. Arch Dis Child. oct 2019;104:998-1003.

8 Deyra M, Gay C, Gerbaud L, et al. Global health determinants perceived and expressed by children and adolescents between 6 and 17 years: a systematic review of qualitative studies. Front Pediatr 2020;8:115.

9 Pridmore P. Visualizing health: exploring perceptions of children using the draw-andwrite method. Promot Educ 1996;3:11-15.

10 Backett $\mathrm{K}$, Alexander $\mathrm{H}$. Talking to young children about health: methods and findings Health Educ J 1991:50:34-8.

11 Pope C, Ziebland S, Mays N. Qualitative research in health care. analysing qualitative data. BMJ 2000;320:114-6.

12 Pizon F. De la face cachée des conceptions en santé : un clair-obscur décisionnel. Mémoire d'Habilitation Diriger des Recherches. Soutenu publiquement le 18 novembre 2017. Service de Santé Publique. Université Clermont-Auvergne, ClermontFerrand 2017.

13 Braveman P, Gottlieb L. The social determinants of health: it's time to consider the causes of the causes. Public Health Rep 2014;129 Suppl 2:19-31.

14 Varmus $\mathrm{H}$, Kumar HS. Addressing the growing international challenge of cancer: a multinational perspective. Sci Trans/ Med 2013;5:175cm2.

15 Greaves M. Evolutionary determinants of cancer. Cancer Discov 2015;5:806-20.

16 Braveman P, Egerter S, Williams DR. The social determinants of health: coming of age. Annu Rev Public Health 2011;32:381-98.

17 PIZON F, BRUN-PERRIN M, PIRONOM J. Essai de catégorisation des conceptions individuelles d'enfants scolarisés en cycle 3 (CE2-CM1-CM2) dans le domaine de la santé. Éducations, santé et mutations sociales : nouveaux enjeux, nouveaux défis ? 5ème colloque international d'UNIRéS, Oct 2014. Paris, France, 2016.

18 Pizon F. Prévention des addictions: regards pluriels. Vol. 5. Revue Education, Santé, Sociétés 2018.

19 Pizon F. Education la santé et prévention. London: ISTE, 2018: 174p. (Santé et patients; vol. 3)

20 Bardin L. L'analyse de contenu. Paris: PUF, 2007.

21 Angell C, Alexander J, Hunt JA. 'Draw, write and tell': A literature review and methodological development on the 'draw and write' research method. Journal of Early Childhood Research 2015;13:17-28.

22 Brown KF, Rumgay H, Dunlop C, et al. The fraction of cancer attributable to modifiable risk factors in England, Wales, Scotland, Northern Ireland, and the United Kingdom in 2015. Br J Cancer 2018;118:1130-41.

23 Emond Aet al. Cadre conceptuel de la santé et de ses déterminants : résultat d'une réflexion commune. Ministère de la santé et des services sociaux Québec, 2010.

24 Lynch JW, Law C, Brinkman S, et al. Inequalities in child healthy development: some challenges for effective implementation. Soc Sci Med 2010;71:1244-8.

25 Marmot M, Friel S, Bell R, et al. Commission on social determinants of health. closing the gap in a generation: health equity through action on the social determinants ofhealth. Lancet Lond Engl. 8 nov 2008;372:1661-9.

26 Sheiham A. Closing the gap in a generation: health equity through action on the social determinants of health. A report of the who Commission on social determinants of health (CSDH) 2008. Community Dent Health 2009;26:2-3.

27 Vygotski L. Pensée et langage (f. Sève, TraD. Troisième édn. Paris: La Dispute, 1934. 